\title{
editorial
}

\section{Then and now}

$\mathrm{F}$ orty years ago, on July 12, 1964 , EM BO was officially registered under Swiss law as an association of scientists. I do not know if those who brought EMBO to life opened a champagne bottle to celebrate this final step, but I doubt it. The founders of EMBO were very much focused on their task - to move forward the biological sciences in Europe. The organization had two distinctive features: it thought of science in terms of Europe, not nation states (a very unusual perspective then), and it proselytized for a different, molecular-level, approach to the study of biology. EMBO was set up as a vehicle to support the scientific community in Europe- and little has changed since.

Last month, we had a special meeting to celebrate EMBO's 40th birthday. It brought together many of the main players in those events 40 years ago with the later generations of our members, and stimulated great discussions about how molecular biology has evolved over the past four decades. O ne intriguing change over this time is that today research in all areas of the biosciences is predominantly on a molecular scale. So, it is appropriate to reflect on the role of EMBO in European biological research and how this too has changed over time to meet new challenges.

Back in 1964, describing the diversity of plants, the development of an animal or the reaction carried out by an enzyme was state of the art in biological research. But EMBO's founders tried to move the research agenda forwards by finding mechanistic explanations for these observations: why were plants different, what molecules were involved in determining how an animal developed and how does an enzyme change its structure to carry out a chemical reaction? Answering such questions required not only new techniques, but also a new way of looking at research and defining its goals-hence the need for a new organization dedicated to molecular biology. O ne consequence of this change in direction was that historical barriers between, for example, zoologists and microbiologists, did not make any further sense as the focus gradually shifted to look at the basic molecular mechanisms that all organisms use to live, grow and proliferate.

Forty years ago, it was not yet clear if 'molecular biology' was the right name for these developments in research-until September 1963, EMBO was informally called the European Organization of Fundamental Biology. Today, we are witnessing another melting of disciplinary boundaries. This time, the increasing interaction between biologists and chemists, physicists, mathematicians and computer experts creates new research fields and opportunities. The new shorthand word for this dynamic integration of molecular studies is 'systems biology'. The new research directions are clear: the availability of massive data sets, increased quantification, a move from two-dimensional analyses to the incorporation of the four dimensions (with time being an increasingly essential axis) and the greater involvement of computer biologists and those outside biological sciences. Everything is in place for the next revolution in biology, and 'molecular biologists' are at the core of this change.

The founders of EMBO believed that the instruments required to bring about changes in bioresearch in Europe were a European laboratory, international cooperation and mobility of scientists. The laboratory, EMBL, was founded then only 10 years after EMBO and has since proven its enormous importance for biological research in Europe.

The mobility needs that lead to the integration of European science have been met by EMBO Fellowships, and Courses and Workshops that allow researchers to meet and learn from each other. Another change in this regard-that was not anticipated 40 years ago-is the increasing importance of electronic communication. Although it will never be able to replace person-to-person conversations during a meeting or at the laboratory bench, EM BO 's activities in electronic communication reflect the value of this new medium and have generated several projects to aid scientists in their research. And EMBO's other new activities focusing on young independent scientists, the interplay between science and society, developing links with molecular biology laboratories worldwide and encouraging an increased involvement of women in research complete a palette of actions that respond to the changing needs of researchers.

Clearly, the financial and political support from many European countries has enabled all these activities to come to life. But this was initially given in competition with other suitors. In the 1960s, the World Health Organization and the United Nations Educational, Scientific and Cultural O rganization (UN ESCO ) advanced plans for a scientific programme and laboratory in molecular biology. But the political conjunction of stars in the 1960s led decisionmakers to eventually agree on a European initiative to advance molecular biology. As a result, the European Molecular Biology Conference (EMBC) was created 35 years ago to fund EMBO's activities and to establish the EMBL.

The founders of EMBO showed an incredible vision when they established the organization against all obstacles and criticism. They were true motors of change, even revolutionaries, who raised biological research to a European level while sticking to the highest standards of scientific excellence. Keeping faith with their vision, their principles and standards are a guide to our activities today and the best monument to the memories of all those who created EM BO 40 years ago.

\section{Frank Gannon}

doi:10.1038/sj.embor.7400214 